\title{
Evaluación biológica de una fracción de la esponja marina Topsentia ophiraphidites del Caribe colombiano
}

\section{Biological evaluation of a fraction from the colombian Caribbean sponge Topsentia ophiraphidites}

\author{
Lina Blandón G, ${ }^{1 *}$ M.Sc, Diana Márquez F, ${ }^{2}$ Ph.D, Juan López $0,{ }^{1}$ M.Sc, \\ Maria Márquez $F_{1}{ }^{1}$ M.Sc.
}

\begin{abstract}
${ }^{1}$ Universidad Nacional de Colombia, Facultad de Ciencias, Grupo Biotecnología Animal, Línea Bioactividad de Productos Naturales y Sintéticos. Medellín, Colombia. ${ }^{2}$ Universidad de Antioquia, Facultad de Química Farmacéutica, Departamento de Farmacia, Grupo de Productos Naturales Marinos. Medellín, Colombia. *Correspondencia: Imblando@unal.edu.co
\end{abstract}

Recibido: Septiembre de 2012; Aceptado: Abril de 2013.

\section{RESUMEN}

Objetivo. Evaluar la actividad antiproliferativa y genotóxica de una fracción con actividad citotóxica obtenida de la esponja marina del Caribe colombiano Topsentia ophiraphidites (Fracción T4). Materiales y métodos. La fracción T4 de la esponja marina Topsentia ophiraphidites fue obtenida en el laboratorio de Productos Naturales Marinos de la Universidad de Antioquia. La actividad antiproliferativa se evaluó mediante ensayos de eficiencia de clonación, función de acumulación y cinética proliferativa por intercambio de cromátidas hermanas (ICH); la actividad genotóxica se evaluó mediante electroforesis en gel de células individuales (Ensayo cometa) e intercambio de cromátidas hermanas (ICH). Todas las pruebas fueron realizadas sobre las líneas celulares Jurkat y CHO. Resultados. La fracción T4 afectó el ciclo celular de las células $\mathrm{CHO}$ y mostró daño genotóxica crónico en las células Jurkat. Conclusiones. Se recomienda la evaluación de la fracción T4 en otras líneas celulares derivadas de tumor con el fin de determinar un posible efecto diferencial, además de evaluar otras actividades de tipo antimicrobiano, antimalárico, entre otros.

Palabras clave: Citotoxicidad, esponja, genotoxicidad, peces marinos (Fuente: CAB).

\begin{abstract}
Objective. To evaluate the antiproliferative and genotoxic activity of a fraction (T4 fraction) of the Colombian Caribbean marine sponge Topsentia ophiraphidites, with cytotoxic activity. Materials and methods. T4 fraction from the marine sponge Topsentia ophiraphidites was provided by the group of marine natural products from Universidad de Antioquia. The antiproliferative activity was evaluated by cloning efficiency tests, accumulation function, and proliferative kinetics by sister chromatid exchange (SCE), genotoxic activity was evaluated by SCE and gel electrophoresis of individual cells (Comet assay). All tests were performed on Jurkat and $\mathrm{CHO}$ cell lines. Results. The T4 fraction affected the cell cycle of $\mathrm{CHO}$ cells and presented chronic genotoxic damage in Jurkat cells. Conclusions. It is recommended to evaluate the T4 fraction in other derived tumor cell lines, in order to observe a possible differential effect, and to evaluate antimicrobial and antimalarial activities among others.
\end{abstract}

Key words: Cytotoxicity, genotoxicity, marine fisheries, sponge (Source: $C A B$ ). 


\section{INTRODUCCIÓN}

Una de las principales causas de muerte en países en desarrollo es el cáncer, enfermedad que consiste en un crecimiento sin control de las células. Los medicamentos usados para el tratamiento de la enfermedad han mostrado baja eficacia, especificidad limitada, daños en células y tejidos no cancerosos y generan resistencia a tratamientos como la quimioterapia (1).

En las últimas décadas, se ha incrementado la búsqueda de nuevas sustancias de origen natural con potencial antitumoral como alternativas de tratamiento. Debido a su gran diversidad biológica y química, los océanos constituyen una fuente inmensa para la búsqueda de fármacos antitumorales y las esponjas marinas son los organismos de estudio más promisorios ya que gracias a su naturaleza sésil y mecanismo de protección a predadores, producen metabolitos secundarios con gran potencial antitumoral (2-5).

A partir de las esponjas marinas se ha logrado obtener una gran cantidad de sustancias con potencial antitumoral (6). El análogo ara - C sintetizado a partir de los nucleósidos espongotimidina y espongouridina extraídos de las esponja Cryptotethia cripta es quizás uno de los compuestos más usados en el tratamiento de la leucemia mieloide aguda y su análogo fluorado Gemcitabina, es una importante herramienta terapéutica en el tratamiento del cáncer pancreático y de pulmón (7). Otras sustancias que han mostrado actividad antitumoral se encuentran en etapa preclínica avanzada, como las topsentinas (aislada de Topsentia genitrix, Spongosorites sp. y Hexadella sp.), la debromohymenialdisina (aislada de Plakellia flabellata, Hymeniacidon aldis y Stylotella aurantia), la halichondrina B (aislada de Halichondria okadai), la jasplakilonida (aislada de Jaspis sp. o Dorypleres splendens), el discodermolido (aislado de Discodermia dissoluta) y el mycaperóxido B (aislado de Mycale sp.). Otros compuestos también aislados de esponjas marinas, como la isohomohalichondrina B, las espongistatinas y la lamellarina $\mathrm{N}$, así como, un alcaloide citotóxico aislado de Biemna sp. y las bastadinas (aisladas de Ianthella sp.) han mostrado actividad in vitro contra líneas de células tumorales (8).

Por lo anterior, con el fin de contribuir con el conocimiento de la actividad biológica de las esponjas marinas colombianas, en este trabajo se evaluó el potencial antiproliferativo y genotóxico in vitro en las líneas celulares establecidas $\mathrm{CHO}$ y Jurkat de la fracción citotóxica T4 obtenida de la esponja marina Topsentia ophiraphidites colectada en el Golfo de Urabá (Caribe colombiano).

\section{MATERIALES Y MÉTODOS}

Sitio de estudio y muestra. La muestra de la esponja Topsentia ophiraphidites fue recolectada mediante buceo autónomo en el Golfo de Urabá (Colombia) a una profundidad de 15-21 metros en 2002; luego se limpiaron cuidadosamente y posteriormente se conservaron a una temperatura de $4^{\circ} \mathrm{C}$ y protegidas de la luz. Una parte de la muestra se encuentra en el Laboratorio de Productos Naturales de la Universidad de Antioquia.

Preparación de extractos y tratamientos celulares. La muestra de esponja fue cortada en pequeños pedazos y secada a una temperatura inferior a $40^{\circ} \mathrm{C}$. La muestra seca se sometió a extracción inicialmente con diclorometano y posteriormente con etanol. Cada extracto fue filtrado y concentrado hasta sequedad a una temperatura no mayor de $40^{\circ} \mathrm{C}$, utilizando agitación constante y presión reducida. Los extractos secos obtenidos se conservaron refrigerados, protegidos de la luz, del aire, del calor y de la humedad.

El extracto etanólico de la esponja se sometió a fraccionamiento por cromatografía en columna instantánea en la cual la fase estacionaria fue sílica gel $\mathrm{C}_{18}$ y como fase móvil se utilizaron $500 \mathrm{ml}$ de la siguiente serie elutrópica: agua, agua/metanol (1:1), agua/metanol (1:3), metanol, metanol/diclorometano (3:1), metanol/ diclorometano (1:1) y diclorometano. Cada fracción se concentró hasta sequedad a una temperatura no mayor de $40^{\circ} \mathrm{C}$, utilizando agitación constante y presión reducida. Las fracciones se nombraron en el mismo orden en que se hizo la elución con cada solvente, así: T1, T2, T3, T4, T5, T6 y T7. Las fracciones fueron diluídas en dimetilsulfóxido (DMSO) de donde se obtuvo una solución stock inicial de $40 \mathrm{mg} / \mathrm{ml}$, de la cual se realizaron diluciones seriadas en medio simple (RPMI 1640, Gibco), con las que se trataron las dos líneas celulares durante 20 horas (equivalentes a un ciclo celular). De todas las fracciones, la T4 fue la fracción que mostró mayor efecto citotóxico (9) por esa razón se requiere evaluar su potencial antiproliferativo y genotóxico.

Líneas celulares. Para la realización de las pruebas antiproliferativas y genotóxicas (ensayo cometa e intercambio de cromátides hermanas) se empleó la línea celular CHO-K1 (ATCC CCL61) la cual es un subclón de la línea parental CHO derivada de ovario de hámster chino, crece adherida al sustrato y la línea celular Jurkat (ATCC TIB-152) de origen leucemoide, establecida de células de sangre periférica de un 
niño de catorce años con leucemia aguda, crece en suspensión, adopta morfología de linfoblasto y forma racimo $(10,11)$.

Las líneas celulares fueron mantenidas en medio RPMI 1640 suplementado con $5 \%(\mathrm{v} / \mathrm{v})$ de suero bovino fetal (SBF), en atmósfera húmeda con $\mathrm{CO}_{2}$ al $5 \%(\mathrm{v} / \mathrm{v})$ (Jurkat) e incubadas a $37^{\circ} \mathrm{C}$ (condiciones estándar). Todos los experimentos se realizaron con la viabilidad igual o superior al $95 \%$ y con los cultivos en fase exponencial de crecimiento.

Evaluación del efecto antiproliferativo. Para evaluar el efecto antiproliferativo de la fracción T4 se realizaron las pruebas de eficiencia de clonación, función de acumulación y cinética proliferativa por intercambio de cromátidas hermanas (ICH) y se tomaron concentraciones iguales o menores que la $\mathrm{IC}_{50}$ encontrada con las pruebas citotóxicas (9) con el fin de obtener una población celular mayor del $50 \%$ que fuese posible evaluar.

Eficiencia de clonación en células CHO. La prueba consiste en tratar las células con la concentración de la sustancia a evaluar, durante un tiempo equivalente a un ciclo celular, luego éstas se cuentan y se diluyen para sembrarlas de nuevo a baja densidad ( 200 a 400 células/plato multipozo de 6 pozos). Después de 15 días de incubación en condiciones de cultivo estándar, se evalúa el efecto de antiproliferación por conteo del número de colonias de cada cultivo tratado respecto al control negativo (células sin tratar)(12).

El protocolo empleado para la eficiencia de clonación en células $\mathrm{CHO}$ fue basado en el reportado por Fresney (12) con modificaciones. Cultivos de células $\mathrm{CHO}$ en fase exponencial de crecimiento y subconfluentes fueron tratados con las diferentes concentraciones $(58 \mu \mathrm{g} / \mathrm{ml}$ ó $\mathrm{IC}_{50}, 52 \mu \mathrm{g} / \mathrm{ml}, 29 \mu \mathrm{g} / \mathrm{ml}$ ) de la fracción T4, desprendidas con tripsina (1X, Gibco), luego contadas y su viabilidad evaluada con azul de tripano al $0.4 \%(\mathrm{v} / \mathrm{v})$. Las células fueron sembradas en una dilución de 200 células/ pozo en platos de 6 pozos en $2.5 \mathrm{ml}$ de medio RPMI 1640 suplementado con $5 \%(\mathrm{v} / \mathrm{v})$ de SBF e incubadas a $37^{\circ} \mathrm{C}$ durante 15 días. Después de este tiempo, se contabilizaron las colonias, se colorearon con cristal violeta (Sigma) al 4\% (p/v) y luego se calculó la Eficiencia de Clonación Absoluta (ECA) y la Eficiencia de Clonación Relativa (ECR) con las ecuaciones 1 y 2 (12).

$E C A=\frac{\text { No Colonias Contadas }}{\text { No Colonias Sembradas }} * 100(1)$
$E C R=\frac{\text { Eficiencia de Clonación Absoluta del Tratamiento }}{\text { Eficiencia de Clonación Absoluta del Control Negativo }} * 100$

Eficiencia de clonación en células Jurkat. El protocolo empleado para la eficiencia de clonación en células Jurkat fue basado en el reportado por Fresney (12) con modificaciones. Las células Jurkat de un cultivo subconfluente tratado con las concentraciones $\left(33 \mu \mathrm{g} / \mathrm{ml}\right.$ o IC I0 $_{50}, 30 \mu \mathrm{g} / \mathrm{ml}$ y $17 \mu \mathrm{g} / \mathrm{ml}$ ) de la fracción T4, fueron contadas y se determinó su viabilidad con azul de tripano al $0.4 \%(\mathrm{v} / \mathrm{v})$. Luego las células se sembraron en una dilución de 300 células/pozo en platos de 6 pozos que contenían una primera capa de medio RPMI- 1640 suplementado con $10 \%$ (v/v) de SBF y agar - agar al $0.6 \%$ ( $p / v)$ (medio semisólido), de manera que las células fueron adicionadas en una segunda capa de medio de cultivo RPMI-1640 suplementado con SBF al $10 \%(\mathrm{p} / \mathrm{v})$ y con agar - agar al 0.3\% ( $\mathrm{p} / \mathrm{v})$, (medio semisólido). Las células se incubaron a $37^{\circ} \mathrm{C}$ en atmósfera de $\mathrm{CO}_{2}$ al $5 \%(\mathrm{v} / \mathrm{v})$ durante 15 días, después de lo cual se contaron las colonias formadas. Los cálculos de la ECA y ECR se realizaron de acuerdo con las ecuaciones 1 y 2 respectivamente.

Los controles utilizados para esta prueba, en ambas líneas celulares fueron el control del solvente (DMSO $[0.03 \%(p / v)]$ ) y un control negativo (células sin tratar).

Función de acumulación. La función de acumulación se obtiene después de tratar un cultivo celular con una sustancia a evaluar por un tiempo equivalente a un ciclo celular y posteriormente bloquearlo con un antimitótico durante otro período, equivalente a otro ciclo celular. Finalmente, se realiza una curva con los datos obtenidos, y el período en el cual se llega a la fase estacionaria de la curva, permite calcular el tiempo de generación (Tiempo en el cual se demora una célula en realizar el ciclo celular) y determinar de acuerdo al comportamiento de la pendiente, que tan largo o corto es el ciclo celular respecto al control no tratado con las fracciones. Esta información permite inferir el potencial efecto inhibitorio o acelerador de una sustancia que se quiera evaluar (13).

Se usó el protocolo propuesto por Puck y Steffen (13) con algunas modificaciones. Cultivos en crecimiento exponencial y subconfluentes de ambas líneas celulares, fueron tratados con la fracción T4 a las concentraciones de $29 \mu \mathrm{g} / \mathrm{ml}$ y $17 \mu \mathrm{g} / \mathrm{ml}$ para las células $\mathrm{CHO}$ y Jurkat respectivamente, equivalentes a la mitad de las $\mathrm{IC}_{50}$ encontradas con la prueba citotóxica de MTT (9). Posteriormente, se adicionó el antimitótico Colcemid $(0.1 \%(p / v), G \& M)$, se cosecharon y se obtuvieron extendidos cromosómicos por la técnica citogénetica convencional 
(14), cada dos horas durante 14 horas para células $\mathrm{CHO}$ y cada dos horas durante 18 horas para células Jurkat, tiempos equivalentes al ciclo celular de cada una de ellas. Se realizó un control negativo (células sin tratamiento) y un control del solvente (DMSO $[0.03 \%(\mathrm{p} / \mathrm{v})]$ ). En cada tratamiento se determinó el índice mitótico (IM) en 1000 células contadas (Ecuación 3).

$$
I M=\frac{\text { No Mitosis Encontradas }}{\text { No Células Totales }} * 100(3)
$$

Cinética proliferativa mediante ICH. La técnica consiste en cambiar la estructura química de un cromosoma incorporando un análogo de la timidina, denominado 5-bromo-2-deoxiuridina (BrdU), durante dos ciclos celulares, lo cual puede ser visualizado con tinción diferencial Giemsa. En un primer ciclo de incorporación del BrdU, se logrará la sustitución de la timidina en las cromátidas hermanas, en el siguiente ciclo de duplicación, se tendrá una cromátida monosustituida (de coloración oscura) mientras que la otra será bisustituida (de coloración pálida), lográndo una diferenciación química de las dos cromátidas. La coloración diferencial permite visualizar los intercambios ocurridos entre las cromátidas hermanas (15).

Teniendo en cuenta que la prueba de cinética proliferativa por ICH es de tratamiento largo (dos a tres ciclos celulares), mientras que la de eficiencia de clonación es de un único ciclo, se pretendía evaluar el efecto sobre el ciclo celular dependiente de la dosis de la fracción, para determinar su efecto a medianas y bajas concentraciones comparadas con la IC50. En el experimento, las células fueron sembradas y después de 36 horas, se adicionó BrdU (1 $\mathrm{mg} / \mathrm{ml}$, Sigma), luego de un ciclo de replicación (36 ó 60 horas para $\mathrm{CHO}$ y Jurkat, respectivamente), las células fueron tratadas con concentraciones de $33 \mu \mathrm{g} / \mathrm{ml}$ ( IC $_{50}$ ), $17 \mu \mathrm{g} / \mathrm{ml}, 8$ $\mu \mathrm{g} / \mathrm{ml}$ (células Jurkat) y $58 \mu \mathrm{g} / \mathrm{ml}\left(\mathrm{IC}_{50}\right), 29 \mu \mathrm{g} / \mathrm{ml}$, $17 \mu \mathrm{g} / \mathrm{ml}$ (Células $\mathrm{CHO}$ ) durante un ciclo adicional de replicación. Una hora antes de la obtención de las preparaciones cromosómicas, las células fueron tratadas con Colcemid $(10 \mu \mathrm{g} / \mathrm{ml})$. Se realizaron los controles negativo (células sin tratamiento), control del solvente (DMSO al 0.03\% (p/v)). Las preparaciones cromosómicas fueron coloreadas diferencialmente, según el protocolo descrito por Salah et al (16). Se evaluaron 60 metafases y se clasificaron en mitosis de medio ciclo $(A)$, un ciclo (B), ciclo y medio (C), dos ciclos (D), tres ciclos (E) y mayores de tres ciclos (F) luego se calculó el número promedio de células y se estimó el tiempo de generación por cada tratamiento (Ecuaciones 4 y 5 ).
No Células Promedio $=\frac{A * 0.5+B * 1+C * 1.5 * D * 2+E * 2.5+F * 3}{\text { No Células Totales }}$

Tiempo de Generación $=\frac{\text { Tiempo de Exposición a BrdU }}{\text { No Células Promedio }}$

Efecto genotóxico por ICH. Se evaluó el efecto genotóxico crónico contabilizando los intercambios entre cromátidas hermanas (ICHs) observados en un promedio de 30 metafases de segundo ciclo (16).

Efecto genotóxico por ensayo cometa. EI ensayo cometa es una técnica empleada para visualizar el daño en el DNA a nivel de células individuales luego de exposición aguda a un agente genotóxico. Para ello, un pequeño número de células son superpuestas entre dos capas de agarosa sobre un portaobjetos, son lisadas para remover proteínas y lípidos, llevadas a electroforesis y finalmente teñidas con un colorante fluorescente, para visualizar el daño en un microscopio de fluorescencia (17).

En este estudio se tomaron 100.000 células de las líneas celulares Jurkat y $\mathrm{CHO}$ en un volumen final de $250 \mu \mathrm{l}$ de medio RPMI 1640 y se trataron con las diferentes concentraciones $(58 \mu \mathrm{g} / \mathrm{ml}, 29 \mu \mathrm{g} / \mathrm{ml}$ y $17 \mu \mathrm{g} / \mathrm{ml}$ para las células $\mathrm{CHO} ; 33 \mu \mathrm{g} / \mathrm{ml}, 17 \mu \mathrm{g} / \mathrm{ml}$ y $8 \mu \mathrm{g} / \mathrm{ml}$ para las células jurkat) de la fracción T4 durante 6 horas con el fin de evaluar el daño agudo sobre el DNA por exposiciones cortas. Se realizaron los controles negativo, positivo $\left(\mathrm{H}_{2} \mathrm{O}_{2} 25 \mu \mathrm{M}\right)$ y del solvente (DMSO $[0.03 \%(\mathrm{p} / \mathrm{v})]$ ). Después del tratamiento, las suspensiones celulares se centrifugaron a $2400 \mathrm{rpm}$ durante $10 \mathrm{~min}$, se retiró el sobrenadante, se mezclaron las células con agarosa de bajo punto de fusión preparada previamente a una concentración de $0.05 \%$, se depositaron sobre un portaobjetos previamente cubierto con agarosa de punto de fusión normal a una concentración de $1 \%(\mathrm{p} / \mathrm{v})$, se cubrieron con cubreobjetos y se incubaron a $4^{\circ} \mathrm{C}$ durante 10 minutos para solidificar la agarosa de bajo punto de fusión. Se retiraron los cubreobjetos y las placas se sumergieron en un tampón de lisis durante una noche. A continuación, las placas se pusieron durante 20 minutos en una cámara de electroforesis con tampón de corrido $(\mathrm{NaOH}$ $10 \mathrm{~N}$, EDTA $200 \mathrm{mM}$ ) y luego se corrieron a 300 $\mathrm{mA}$ durante 30 minutos a $\mathrm{pH}$ 13. Posteriormente, los portaobjetos se deshidrataron con metanol, se tiñeron con Bromuro de etidio $(0.02 \mathrm{mg} / \mathrm{ml}$, Sigma) para su observación en una magnificación de 40X en un microscopio de fluorescencia (Nikon, eclipse 80i). Una vez obtenidas las imágenes, la forma del cometa, muestra la ubicación de los fragmentos de tamaño mayor, respecto a los fragmentos menor tamaño, los cuales se pueden 
clasificar en 5 niveles: El nivel 1, representa una célula sin daño y el nivel 5, el máximo daño. Con ayuda del programa Comet Score se midió el tamaño de la cola de los cometas formados en 60 células por tratamiento, se seleccionó el tamaño de la cola ya que en este caso el daño observado en el DNA era mínimo caso en el que este parámetro es recomendado $(18,19)$.

Análisis estadístico. En cada experimento de eficiencia de clonación se realizaron tres réplicas por tratamiento y cada experimento se realizó por duplicado. El análisis estadístico se basó en la comparación de los promedios de las colonias contadas en los tratamientos y el control negativo, obteniendo la ECA y ECR mediante las ecuaciones 1 y 2 .

La función de acumulación se analizó por regresión lineal para cada tratamiento y los controles negativos de cada línea celular. El eje $Y$ es el log [1+IM] versus el tiempo de exposición de las células al antimitótico (13), lo cual permite linearizar la curva y comparar las pendientes del control negativo y de cada una de las concentraciones evaluadas.

En la cinética proliferativa por $\mathrm{ICH}$ se obtuvieron los tiempos de generación de controles y tratamientos mediante las ecuaciones 4 y 5 . Por otro lado, el efecto genotóxico por ICH y ensayo cometa se analizó mediante un ANOVA de una vía.

\section{RESULTADOS}

Evaluación de efecto antiproliferativo por eficiencia de clonación. En la figura 1, se muestran los resultados de eficiencia de clonación obtenidos para la fracción T4 en las células $\mathrm{CHO}(\mathrm{A})$ y Jurkat $(\mathrm{B})$. Con esta prueba se evaluaron tres concentraciones, la $\mathrm{IC}_{50}$ hallada con las pruebas citotóxicas (7) y dos inferiores a la $\mathrm{IC}_{50}$ en cada una de las líneas celulares: $58 \mu \mathrm{g} / \mathrm{ml}$ (IC50) $52 \mu \mathrm{g} / \mathrm{ml}$ y $29 \mu \mathrm{g} / \mathrm{ml}$ para las células $\mathrm{CHO}$; y para las células Jurkat $33 \mu \mathrm{g} / \mathrm{ml}$ (IC50), $30 \mu \mathrm{g} / \mathrm{ml}$ y $17 \mu \mathrm{g} / \mathrm{ml}$. Las células $\mathrm{CHO}$ mostraron un efecto antiproliferativo dependiente de la dosis.

Evaluación del efecto antiproliferativo por función de acumulación. En la figura 2 se muestran las curvas obtenidas mediante la técnica de función de acumulación, con esta prueba se evaluó una concentración igual a la mitad de la IC $_{50}$ en cada línea celular $(29 \mu \mathrm{g} /$ $\mathrm{ml}$ para las células $\mathrm{CHO}$, y $17 \mu \mathrm{g} / \mathrm{ml}$ para las células Jurkat).
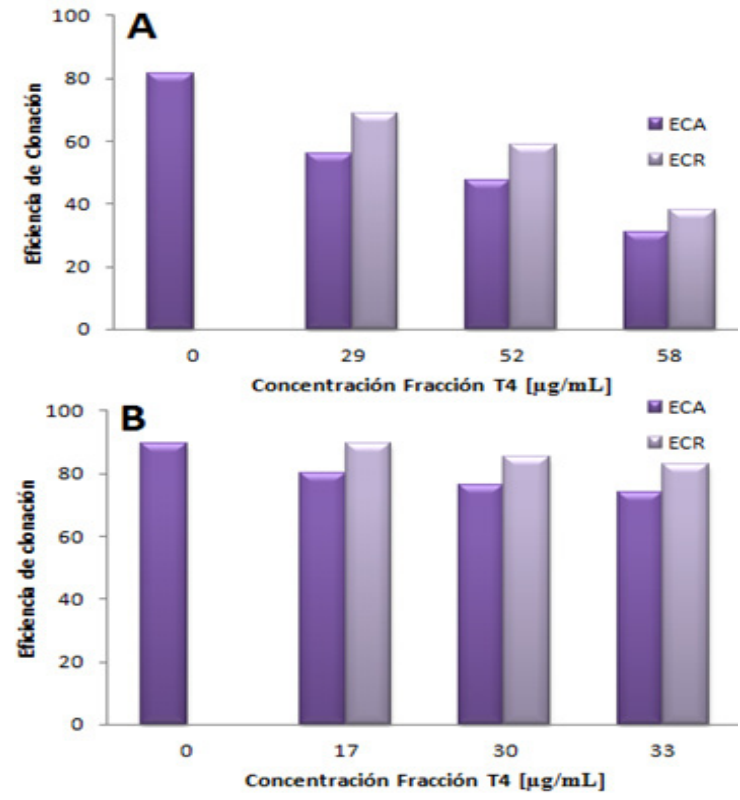

Figura 1. Eficiencia de Clonación Absoluta (ECA) y Relativa (ECR) observada en células $\mathrm{CHO}(\mathrm{A})$ y células Jurkat (B) luego de la exposición durante un ciclo celular a las diferentes concentraciones de la fracción T4. Control negativo células sin tratar $[0 \mu \mathrm{g} / \mathrm{ml}$.

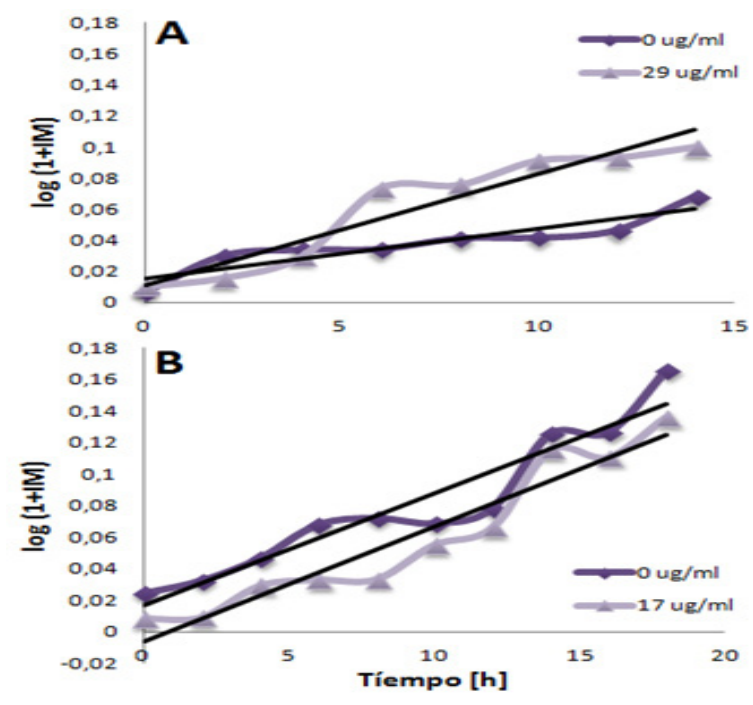

Figura 2. Curvas de acumulación en células $\mathrm{CHO}(\mathrm{A})$ y células Jurkat (B) tratadas durante un ciclo celular con la fracción T4. Control negativo células sin tratar $[0 \mu \mathrm{g} / \mathrm{ml}]$.

Cinética proliferativa por ICH. En la figura 3 se muestran los tiempos de generación obtenidos para cada una de las líneas celulares mediante la prueba de ICH. El tiempo de generación estimado para las células Jurkat con las tres concentraciones evaluadas $(8,17$ y $33 \mu \mathrm{g} / \mathrm{ml})$ fue aproximadamente de 33 horas al igual que 


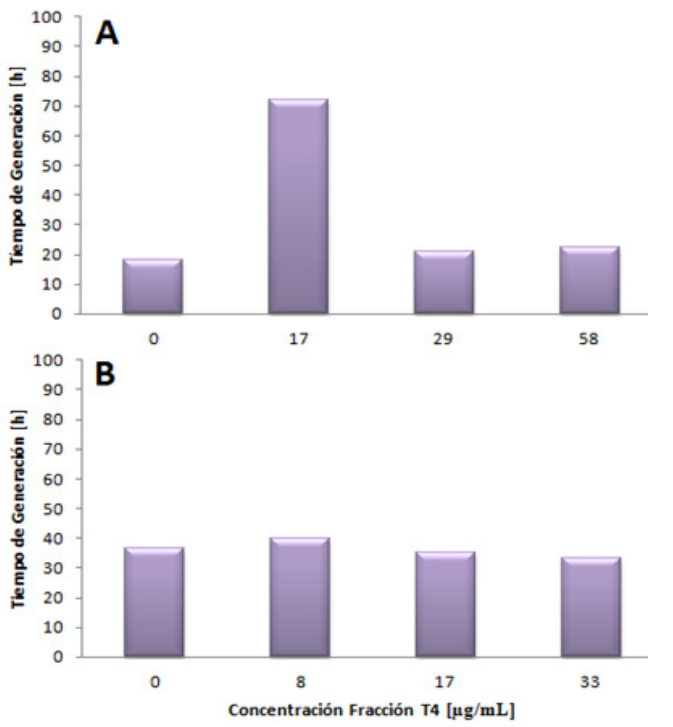

Figura 3. Tiempos de generación estimados mediante $\mathrm{ICH}$ obtenidos de células $\mathrm{CHO}$ tratadas 36 horas (A) y Jurkat tratadas 60 horas (B) con diferentes concentraciones de la fracción T4. Control negativo, células sin tratar $[0 \mu \mathrm{g} / \mathrm{ml}]$.

el hallado para el control negativo, al contrario las células $\mathrm{CHO}$ mostraron valores de tiempo de generación diferentes al del control negativo evidenciándose un retraso prominente en la concentración de $17 \mu \mathrm{g} / \mathrm{ml}$.

Evaluación genotóxica por ICH. En la figura 4, se muestran los resultados obtenidos mediante la prueba de $\mathrm{ICH}$, luego de exponer las células $\mathrm{CHO}$ y Jurkat a las diferentes concentraciones de la fracción T4.

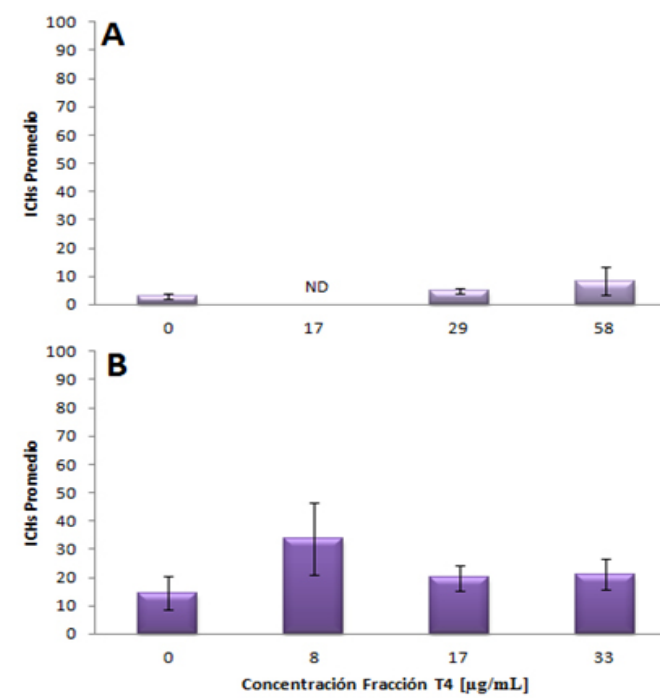

Figura 4. ICHs promedios obtenidos de células $\mathrm{CHO}$ tratadas 36 horas (A) y Jurkat tratadas 60 horas (B) con diferentes concentraciones de la fracción T4. Control negativo, células sin tratar $[0 \mu \mathrm{g} /$ $\mathrm{ml}$. ND: No determinado, todas las metafases observadas estaban en primer ciclo.
Evaluación genotóxica por ensayo cometa. En la figura 5 se muestran los resultados obtenidos mediante el ensayo cometa.
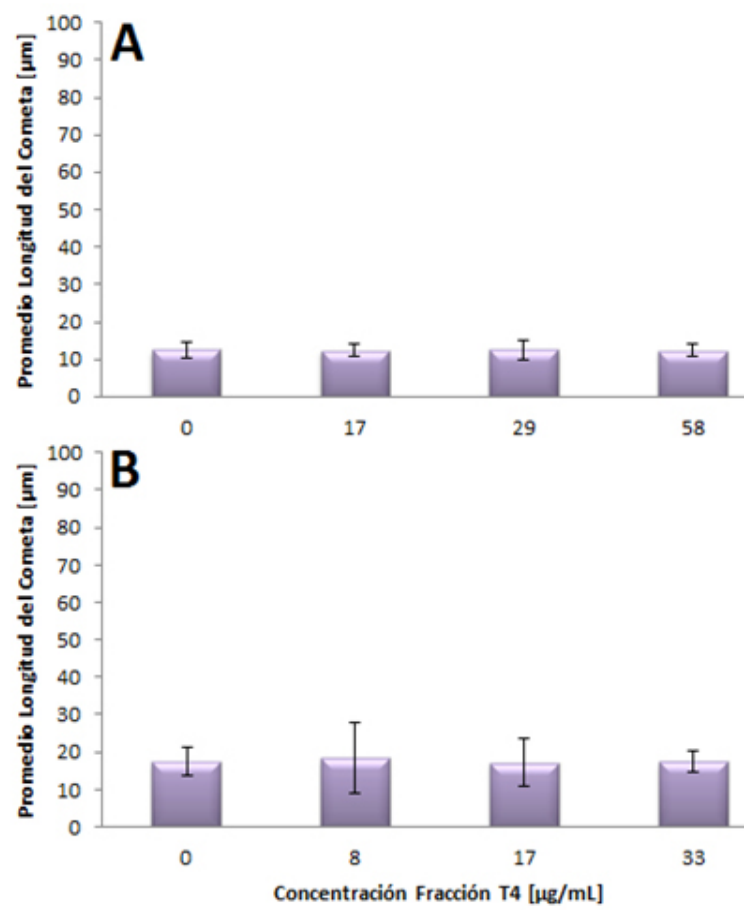

Figura 5. Longitudes promedio del cometa, en células tratadas 6 horas con diferentes concentraciones de la fracción T4. Células $\mathrm{CHO}(\mathrm{A})$ y Jurkat (B). Control negativo, células sin tratar $[0 \mu \mathrm{g} / \mathrm{ml}]$.

Puede observarse que fue mínimo el daño genotóxico de tipo agudo, debido a la similitud en los promedios de la longitud del cometa de las concentraciones evaluadas con las de los controles negativos (células sin tratar $[0 \mu \mathrm{g} / \mathrm{ml}]$ ).

\section{DISCUSIÓN}

La primera evaluación in vitro para encontrar posibles sustancias antitumorales descrita por el Instituto Nacional de Cáncer de los Estados Unidos (NCI) utiliza un panel de líneas celulares derivadas de diferentes tumores, en las cuales se realizan pruebas de citotoxicidad usando un rango de concentraciones de las sustancias candidatas para determinar el grado relativo de inhibición del crecimiento o citotoxicidad en cada línea celular (20). Estas líneas celulares son conocidas como las líneas NCI - 60 y están conformadas por células provenientes de ocho melanomas, seis leucemias, ocho cánceres de mama, dos de próstata, nueve de pulmón, siete de cólon, seis de ovarios, ocho de riñón y seis de cáncer del sistema nervioso central. Con los resultados de las pruebas de citotoxicidad se halla la concentración inhibitoria media $\left(\mathrm{IC}_{50}\right.$ ) 
como la requerida para inhibir el crecimiento celular (21).

Estudios preliminares de los extractos de la esponja marina Topsentia ophiraphidites fueron evaluados mediante el ensayo colorimétrico de la Sulforhodamina B (22) y mostraron efecto in vitro de los extractos y fracciones sobre la viabilidad de líneas celulares tumorales de carcinoma de pulmón A 549, carcinoma de cólon HT29 y cáncer de mama, MDA-MB-231 (23). Por esa razón, la fracción T4 de la esponja marina Topsentia ophiraphidites fue evaluada con las pruebas de MTT y azul de tripano en otras líneas celulares de mamífero como $\mathrm{CHO}$ y Jurkat, en las cuales se encontró bioactividad (9).

Algunos reportes, muestran que las esponjas del género Topsentia producen varios tipos de compuestos, como esteroles, esteroides sulfatados, derivados de ácidos grasos (oxilipinas) y alcaloides especialmente tipo indol $(24,25)$. La esponja $T$. genitrix posee alcaloides tipo indólico, los cuales han mostrado actividad ictiotóxica, antitumoral, antiviral, antiinflamatoria, antimitótica y antibacterial, entre otras $(26,27)$.

Para evaluar el efecto antiproliferativo de la fracción T4 de Topsentia ophiraphidites, en este estudio, se realizaron las pruebas de eficiencia de clonación, cinética proliferativa por ICH y función de acumulación. En la eficiencia de clonación, se evaluaron tres concentraciones, igual e inferiores a la $\mathrm{IC}_{50}$ obtenida con MTT en cada una de las líneas celulares (9). Las células $\mathrm{CHO}$ tratadas con $29 \mu \mathrm{g} / \mathrm{ml}, 52 \mu \mathrm{g} / \mathrm{ml}$ y $58 \mu \mathrm{g} / \mathrm{ml}\left(\mathrm{IC}_{50}\right)$ mostraron un efecto antiproliferativo dependiente de la dosis, es así como a una concentración de $17 \mu \mathrm{g} / \mathrm{ml}$ se obtuvo una ECR de $68.92 \%$ mientras que a una concentración de $58 \mu \mathrm{g} / \mathrm{ml}$ se obtuvo una ECR de $38.15 \%$. Por otro lado, las células Jurkat tratadas con 17,30 y $33 \mu \mathrm{g} / \mathrm{ml}\left(\mathrm{IC}_{50}\right)$, mostraron efecto similar al control negativo. Estos resultados muestran un efecto diferencial en ambas líneas celulares (Figura 1).

En la figura 2, la curva de acumulación correspondiente a la concentración equivalente a la mitad de la $\mathrm{IC}_{50}(29 \mu \mathrm{g} / \mathrm{ml})$ para las células $\mathrm{CHO}$, mostró un efecto distinto al del control negativo (Figura 2A), lo cual sugiere un retraso en el ciclo celular. Por otro lado, la curva de acumulación de las células Jurkat tratadas con $17 \mu \mathrm{g} / \mathrm{ml}$ de la fracción T4 muestra pendiente similar al control negativo, demostrando que el ciclo celular no es retrasado (Figura 2B). Datos concordantes con la eficiencia de clonación.
La prueba de $\mathrm{ICH}$ permitió estimar el tiempo de generación (TG) de 21.98 horas en las células CHO tratadas una concentración de $29 \mu \mathrm{g} /$ $\mathrm{mL}$, por el contrario, el tiempo de generación a una concentración de $17 \mu \mathrm{g} / \mathrm{mL}$ mostró un retraso en el ciclo celular de aproximadamente 54 horas comparado con las 18.63 horas del control negativo. Este resultado aparentemente contradictorio muestra un efecto inverso de dosis y el efecto antiproliferativo encontrado, lo cual podría explicarse con la teoría química de las colisiones de las moléculas en solución, la cual podría facilitar la inactivación de las sustancias cuando se encuentran en gran cantidad, pero a la menor concentración puede afectar las células de manera más eficiente por estar diluida.

De otro lado, el tiempo de generación estimado para las células Jurkat con las concentraciones evaluadas $(8,17$ y $58 \mu \mathrm{g} / \mathrm{ml})$ es de aproximadamente 33 horas, similar al control negativo y no dependiente de la dosis evaluada. En estas células, el gen que codifica para la proteína p53 es mutado y aquellas células con mínimo daño en su DNA, no son detenidas en G2 (28). Por el contrario, las células $\mathrm{CHO}$ normales para el gen p53, pudieron haber sido detenidas en G2 para reparar el daño y luego continuar al siguiente ciclo. Lo anterior, podría explicar los resultados obtenidos con las pruebas de eficiencia de clonación, ICH y función de acumulación, ya que a pesar de haber sufrido daños en su DNA, las células Jurkat continuaron proliferando.

Es bien conocido que la radioterapia o quimioterapia usados como tratamiento del cáncer pueden inducir daños como quiebres de doble cadena en el DNA (29). Dependiendo del tipo de célula y la fase del ciclo celular, hay dos estrategias de reparación, una de ellas es la unión con un extremo no homólogo (NHEJ) y la otra es la recombinación homóloga (HR). Para reparar el daño producido durante la fase $S$, la HR necesita de una cadena homóloga como plantilla sin causar pérdidas en la información genética (30). La prueba del ICH evalúa las HR que reparan el DNA de quiebres de doble cadena (16) evaluando daños genotóxicos de tipo crónico.

El análisis estadístico para la prueba de $\mathrm{ICH}$, (ANOVA, valor $\mathrm{p}<0.05$ ) en las células $\mathrm{CHO}$ y Jurkat demostró que las medias de todos los tratamientos incluida la del control negativo diferían entre sí en ambas líneas celulares, a pesar de que para las células $\mathrm{CHO}$ los promedios de $\mathrm{ICH}$ obtenidos son similares a los del control negativo, el promedio de ICHs de las células Jurkat es dos veces mayor que su control negativo. De lo anterior, podría deducirse que 
el efecto genotóxico crónico es diferencial entre las líneas evaluadas. Aun así, estos resultados, concuerdan con lo planteado sobre las células normales ( $\mathrm{CHO}$ ), las cuales posiblemente fueron detenidas en G2 con el fin de reparar su DNA, lo cual puede corroborarse en la baja concentración (17 $\mu \mathrm{g} / \mathrm{ml})$ donde hubo un retraso en el ciclo celular y no se pudieron visualizar metafases de segundo ciclo.

El ensayo cometa permite detectar daño genotóxico agudo a nivel de células individuales (31), bajo condiciones alcalinas $(\mathrm{pH}>13)$ y puede medir la magnitud de los quiebres de cadena sencilla y dobles en el DNA (32). El análisis estadístico de los resultados obtenidos con el ensayo cometa en las células $\mathrm{CHO}$ y Jurkat muestra que las concentraciones evaluadas de la fracción T4 no generan quiebres en el DNA en comparación con el control negativo. En ambos casos, el ANOVA de una vía $(p>0.05)$ demostró que todas las medias de los diferentes tratamientos y el control negativo no variaban entre sí, lo cual implica que la fracción T4 no generó daño genotóxico agudo sobre las líneas celulares evaluadas. Estos resultados, concuerdan con los resultados diferenciales en la prueba de $\mathrm{ICH}$ para las células $\mathrm{CHO}$ y Jurkat, a pesar de que estas muestran un leve incremento en el número promedio de ICHs comparada con la línea normal $\mathrm{CHO}$.

En conclusión la fracción citotóxica T4 perteneciente a la esponja marina del Caribe colombiano Topsentia ophiraphidites mostró efecto antiproliferativo diferencial sobre la línea celular normal $\mathrm{CHO}$, pero no en la línea derivada de tumor Jurkat. De la misma forma no mostró efecto genotóxico de tipo crónico en las céluas $\mathrm{CHO}$, pero sí un leve efecto en las células Jurkat. Sin embargo, es recomendable evaluarla en otras líneas celulares con el fin de observar un posible efecto diferencial entre ellas y también evaluar otras actividades antimicrobianas, antimalaricas, entre otras.

\section{Agradecimientos}

A la Vicerrectoría de Investigación de la Universidad Nacional en Medellín por la financiación de este proyecto. Al profesor Sven Zea por su valiosa ayuda y colaboración en la identificación del material animal.

\section{REFERENCIAS}

1. Pereira JRCS, Hilário FF, Lima AB, Silveira MLT, Silva LM, Alves RB, et al. Cytotoxicity evaluation of marine alkaloid analogues of viscosaline and theonelladin C. Biomed Prevent Nut 2012; 2(2):145-148.

2. Sepčić K, Kauferstein S, Mebs D, Turk T. Biological activities of aqueous and organic extracts from tropical marine sponges. Marine Drugs 2010; 8(5):1550-1566.

3. Galeano E, Martínez A. Antimicrobial activity of marine sponges from Urabá Gulf, Colombian Caribbean region. J Mycol 2007; 17(1):21-24.

4. Laville R, Thomas OP, Berrue F, Marquez D, Vacelet J, Amade P. Bioactive guanidine alkaloids from two Caribbean marine sponges. J Nat Prod 2009; 72(9):1589-1594.

5. Baerga-Ortiz A. Biotechnology and biochemistry of marine natural products. $\mathrm{P}$ R Health Sci J 2009; 28(3):251-257.

6. Sipkema D, Franssen MC, Osinga R, Tramper J, Wijffels RH. Marine sponges as pharmacy. Mar Biotechnol (NY) 2005; 7(3):142-162.

7. Jimeno J, Aracil M, Tercero JC. Adding pharmacogenomics to the development of new marine-derived anticancer agents. J Translat Med 2006; 4(1):3.

8. Mora J, Zea S, Santos M, Newmark - Umbreit F. Capacidad antimitótica de extractos de esponjas del Caribe colombiano. Bol Invest Mar Cost 2007; 36:167-169.

9. Blandón LM. Evaluación del potencial bioactivo de las esponjas marinas Myrmekioderma gyroderma y Topsentia ophiraphidites. [Tesis de Maestría]. Medellín, Colombia: Universidad Nacional de Colombia, Facultad de Ciencias; Área curricular de Biotecnología; 2012.

10. Cai X, Xing X, Cai J, Chen Q, Wu S, Huang F. Connection between biomechanics and cytoskeleton structure of lymphocyte and Jurkat cells: An AFM study. Micron 2010; 41(3):257-62.

11. Ahn WS, Antoniewicz MR. Parallel labeling experiments with [1,2-13C]glucose and [U-13C] glutamine provide new insights into $\mathrm{CHO}$ cell metabolism. Metabolic Engineering 2013; 15:34-47.

12. Freshney IR. Culture of Animal Cells: A Manual of Basic Technique. United States of America: John Wiley \& Sons Inc; 2005. 
13. Puck TT, Steffen J. Life Cycle Analysis of Mammalian Cells I. A Method for localizing metabolic events within the life cycle, and its application to the action of colcemide ans sublethal doses of X - irradiation. Biophys J 1963; 3:379-397.

14. López JB, Márquez ME. Modelo experimental para el estudio cromosómico en células de mamífero. Medellín- Colombia: Universdad Nacional de Colombia, Facultad de Ciencias; 2002.

15. Orta ML, Mateos S, Cantero G, Wolff LJ, Cortés F. Protection of halogenated DNA from strand breakage and sister-chromatid exchange induced by the topoisomerase I inhibitor camptothecin. Mutation Research/Fundamental and Molecular Mechanisms of Mutagenesis 2008; 637(1-2):40-48.

16. Ben Salah G, Kamoun H, Rebai A, Ben Youssef A, Ayadi H, Belghith-Mahfoudh N, et al. Sister chromatid exchange (SCE) and high-frequency cells (HFC) in peripheral blood lymphocytes of healthy Tunisian smokers. Mutation Research/Genetic Toxicology and Environmental Mutagenesis 2011; 719(1-2):1-6.

17. Speit G, Vasquez M, Hartmann A. The comet assay as an indicator test for germ cell genotoxicity. Mutation Research/Reviews in Mutation Research 2009; 681(1):3-12.

18. Fairbairn DW, Olive $\mathrm{PL}, \mathrm{O}^{\prime}$ Neill $\mathrm{KL}$. The comet assay: a comprehensive review. Mutation Research/Reviews in Genetic Toxicology 1995; 339(1):37-59.

19. Liao W, McNutt MA, Zhu W-G. The comet assay: A sensitive method for detecting DNA damage in individual cells. Methods 2009; 48(1):46-53.

20. Boyd MR. Some practical considerations and applications of the National Cancer Institute In Vitro Anticancer Drug Discovery Screen. Totowa, Nueva Jersey: Teicher Humana Press Inc; 1995.

21. Chakravarti SK, Klopman G.. A structural analysis of the differential cytotoxicity of chemicals in the NCI-60 cancer cell lines. Bioorganic \& Medicinal Chemistry 2008; 16(7):4052-4063.

22. Rubinstein $L$, Shoemaker R, Paull $K$, Simon R, Tosini S, Skehan P, Scudiero D, Monks A, Boyd M. Comparison of in Vitro anticancer - drugscreening data generated with a tetrazolium assay versus a protein assay against a diverse panel of human tumor Cell Lines. 1990. J Natl Cancer Inst 1990; 82:1113-1118.
23. Márquez DM. Estudio Químico y Evaluación Biológica de Esponjas Marinas del Caribe Colombiano. [Tesis Doctoral]. Medellín, Colombia: Universidad de Antioquia, Facultad de Química Farmacéutica; 2009.

24. Guzii AG, Makarieva TN, Denisenko VA, Dmitrenok PS, Burtseva Y, Krasokhin VB, et al. Topsentiasterol sulfates with novel iodinated and chlorinated side chains from the marine sponge Topsentia sp. Tetrahedron Letters 2008; 49(50):7191-7193.

25. McKee TC, Cardellina II JH, Tischler $\mathrm{M}$, Snader KM, Boyd MR. Ibisterol sulfate, a novel HIVinhibitory sulfated sterol from the deep water sponge Topsentia sp. Tetrahedron Letters 1993;34(3):389-392.

26. Gupta L, Talwar A, Chauhan PMS. Bis and tris indole alkaloids from marine organisms: new leads for drug discovery. Current Medicinal Chemistry 2007; 14(16):1789-1803.

27. Mal SK, Bohé L, Achab S. Convenient access to bis-indole alkaloids. Application to the synthesis of topsentins. Tetrahedron 2008;64(25):5904-5914.

28. Siddiqui RA, Jenski LJ, Neff K, Harvey K, Kovacs RJ, Stillwell W. Docosahexaenoic acid induces apoptosis in Jurkat cells by a protein phosphatase-mediated process. Biochimica et Biophysica Acta (BBA). Molecular Cell Research 2001;1499(3):265-275.

29. Clarke PR, Allan LA. Cell-cycle control in the face of damage - a matter of life or death. Trends in Cell Biology 2009; 19(3):89-98.

30. Sjögren C, Ström L. S-phase and DNA damage activated establishment of Sister chromatid cohesion-importance for DNA repair. Experimental Cell Research 2010; 316(9):1445-1453.

31. Speit G, Vásquez M, Hartmann A. The comet assay as an indicator test for germ cell genotoxicity. Mutation Research/Reviews in Mutation Research 2009; 681(1):3-12. DOI dx.doi.org/10.1016/j.mrrev.2008.03.005

32. Rosenberger A, Rössler $U$, Hornhardt S, Sauter W, Bickeböller H, Wichmann H-E, et al. Validation of a fully automated COMET assay: 1.75 million single cells measured over a 5 year period. DNA Repair 2011; 10(3):322-337. 